\title{
First reported case of bacterial endocarditis attributable to Actinomyces meyeri
}

\author{
SUSAN MOFFATT MD, A RAZA AHMEN MD FRCPC, KeVIN FORWARD MD FRCPC
}

\begin{abstract}
S MOFFATT, AR AHMEN, K FORWARD. First reported case of bacterial endocarditis attributable to Actinomyces meyeri. Can J Infect Dis 1996;7(1):71-73. A 48-year-old man presented to the Victoria General Hospital, Halifax, Nova Scotia in severe congestive heart failure. Echocardiographic studies revealed significant aortic valve insufficiency. Two anaerobic blood cultures performed two weeks apart were both positive for Actinomyces meyeri. The patient was treated with high dose intravenous penicillin. Three weeks after antibiotics were begun, he underwent aortic valve replacement. Intraoperative cultures were negative. Histopathological examination revealed findings in keeping with subacute bacterial endocarditis. The patient completed a six-week course of penicillin and was doing well three months after surgery. This is the first case of endocarditis attributable to A meyeri reported in the literature.
\end{abstract}

Key Words: Actinomyces meyeri, Endocarditis

\section{Premier cas déclaré d'endocardite bactérienne attribuable à Actinomyces meyeri}

RÉSUMÉ : Un homme de 48 ans a été amené au Victoria General Hospital de Halifax, en Nouvelle-Écosse, atteint d'une insuffisance cardiaque grave. Les épreuves échocardiographiques ont révélé une insuffisance valvulaire aortique grave. Deux hémocultures anaérobies ont été effectuées à deux semaines d'intervalle et se sont révélées positives à l'égard d'Actinomyces meyeri. Le patient a été traité à l'aide de pénicilline intraveineuse à fortes doses. Trois semaines après le début de l'antibiothérapie, il a subi un remplacement valvulaire aortique. Les cultures peropératoires se sont révélées négatives. L'examen histopathologique a révélé des signes concordant avec une endocardite bactérienne subaiguë. Le patient a mené à terme une antibiothérapie de six semaines à l'aide de pénicilline et se portait bien trois mois après l'intervention. Il s'agit du premier cas d'endocardite attribuable à A. meyeri rapporté dans la littérature.

$\mathrm{T}$ he genus Actinomyces comprises 13 species of Grampositive nonspore-forming bacteria that are obligate or facultative anaerobes. Actinomyces meyeri represent a recently described genus whose principal habitat is the human periodontal sulci (1). It has been isolated from brain, liver and breast abscesses, pleural fluid, skin and soft tissue infections and from bite wounds (1-6). Disseminated infection has also been described $(7,8)$. Although eight cases of endocarditis due to actinomycosis have been described in the English literature, endocarditis due to A meyeri has not been previously described (9). No cases of A meyeri endocarditis were identified in a review of Cumulative Index Medicus or in a MEDLINE search and review of bibliographies from relevant cited publications. We report the first case attributed to A meyeri.

Departments of Microbiology and Immunology, Surgery and Pathology, Dalhousie University; and the Department of Pathology and Laboratory Medicine, Queen Elizabeth II Health Sciences Centre, Halifax, Nova Scotia

Correspondence: Dr Kevin Forward, Department of Microbiology, Victoria General Hospital, Halifax, Nova Scotia B3H 2Y9. Telephone 902-428-3624, fax 902-428-4432, e-mail kforward@ac.dal.ca

Received for publication March 29, 1995. Accepted August 10, 1995 


\section{CASE PRESENTATION}

A 48-year-old man with long-standing rheumatoid arthritis presented with an acute onset of severe shortness of breath. He denied having had fever or other constitutional symptoms suggestive of infection. There was no history of recent dental work or other invasive procedures.

On examination, he was afebrile. There was clinical evidence of congestive heart failure and aortic valve insufficiency. There were no peripheral manifestations of bacterial endocarditis and no lymphadenopathy. The liver and spleen were not enlarged. The patient had extensive deforming rheumatoid arthritis with no actively inflamed joints.

White blood cell count was $13.2 \times 10^{9} / \mathrm{L}$, hemoglobin was $118 \mathrm{~g} / \mathrm{L}$ and platelets were $224 \times 10^{9} / \mathrm{L}$. Sedimentation rate was $70 \mathrm{~mm} / \mathrm{h}$. Urinalysis showed three to five white blood cells/high power field (HPF), zero to one red blood cell/HPF, zero to two hyaline cast/HPF and was negative for protein. An electrocardiogram showed evidence of left ventricular hypertrophy. A chest x-ray revealed evidence of congestive cardiac failure. An echocardiogram showed severe aortic insufficiency and mild stenosis. No vegetations were noted. The left ventricle was dilated and there was generalized hypokinesis.

The patient had a past history of renal cell carcinoma. He had had recurrent nephrolithiasis due to hyperuricemia. Two years before admission, the patient had a liver abscess, which was drained surgically and treated with a prolonged course of antibiotics. Aerobic and anaerobic cultures of the material aspirated from the liver abscess grew Staphylococcus aureus and Streptococcus mitis.

Medications on admission included diclofenac, sulphasalazine hydroxy-chloroquine, allopurinol and ranitidine.

The patient was admitted to hospital and treated for congestive cardiac failure.

Two sets of blood cultures were obtained; one on admission and another two days later. Blood cultures were done in aerobic Bactec Plus/F and Bactec standard anaerobic/F vials on the Bactec 9240 system (Becton Dickinson Canada Inc). Since the patient was not identified as a likely case of endocarditis, blood cultures were examined for only five days and were not subjected to terminal subculture. A meyeri was recovered from the second of the anaerobic vials. This was considered likely to be a contaminant and the patient was discharged in stable condition with a scheduled elective aortic valve replacement.

At home, the patient was able to return to work. He complained of no constitutional symptoms suggesting ongoing infection. Two weeks after discharge a follow-up blood culture was performed. Again, A meyeri was isolated from the anaerobic vial. Physical findings were essentially unchanged from the previous discharge. There was no evidence of congestive heart failure. He was afebrile and had no peripheral manifestations of infective endocarditis. The patient was readmitted to hospital and treated with penicillin 3,000,000 units intravenously every $4 \mathrm{~h}$.

Clinical and radiological assessment by an oral surgeon revealed no dental source for infection. Hepatic ultrasound examination was negative.
The patient developed progressive, uncontrolled congestive heart failure and required aortic valve replacement after three weeks of penicillin treatment. At the time of surgery the aortic valve was found to be tricuspid. At the base of the leaflet, there was a small abscess cavity. The aortic valve was replaced with a homograft. Histological examination showed a mixed inflammatory infiltrate of lymphocytes, histiocytes and plasma cells mixed with necrotic cellular and nuclear debris and granulation tissue. No definite microorganisms could be identified on light or electron microscopy. Aerobic and anaerobic cultures were negative after five days' incubation. The overall morphological findings were consistent with a subacute endocarditis.

The patient's postoperative course was unremarkable and he received another three weeks of intravenous penicillin. In follow-up of the patient, he remained well with no signs of recurrent endocarditis.

\section{DISCUSSION}

Endocarditis due to Actinomyces species is rare. Lam et al (9) reported a case of primary endocarditis due to Actinomyces israelii and reviewed seven other cases of endocarditis reported since 1939. Included among these were two due to A israelii, two due to Actinomyces bovis, one due to Actinomyces viscosus and three that had not been adequately speciated. In three of the eight patients no identifiable risk factor was present. Two patients had extensive caries and three had underlying valvular heart disease.

The proposal for a species designation for A meyeri was presented in 1984 (1). Until then, the most widely accepted classification system included A meyeri within the genus A israelii. In addition to morphological, cultural and biochemical characteristics, strains were separated from A israelii and other Actinomyetes species with a monovalent fluorescent conjugate prepared against an original Prevot stain (1). They are short, Gram-positive, nonspore-forming, nonmobile rods that may occur in pairs, chains or clumps. The organism grows well on brain-heart infusion blood agar plates, producing alpha or nonhemolytic colonies. Growth is abundant on plates incubated anaerobically, but less luxurious when plates are incubated in the presence of $5 \%$ carbon dioxide. Our isolate was identified as A meyeri using the Rapid ANA II system (Innovative Diagnostic Systems, Inc, Georgia) (biocode 02054 98.4\% A meyeri). Other investigators have shown that using the Rapid ANA II, 31 of 31 strains tested had the same biochemical profile as with conventional methods (10). Therefore, we did not repeat the identification with conventional biochemicals. Although originally described as not growing aerobically, strains with a similar biochemical profile growing slowly in air have been described more recently (10). A meyeri can be distinguished from $\mathrm{A}$ israelii and from Actinomyces naeslundii by its inability to ferment raffinose, from Actinomyces odontolyticus by its inability to reduce nitrate, from A viscosus by producing catalase and from A bovis by fermenting xylose and ribose. To date, A meyeri has been reported from patients with liver abscesses, cervical, facial and thoracic actinomycosis, brain and breast abscesses, and os- 
teomyelitis (1-6). Marty and Wust (8) described a case of disseminated A meyeri infections in a previously healthy 35-year-old man.

In the present case, there was no clinically apparent source of infection. The patient had no recent dental manipulations and had good oral hygiene. The patient had previously had a liver abscess; however, culture of the liver abscess had revealed that it was due to $S$ aureus and $S$ mitis, and ultrasound examination of the liver and biliary tract performed on this occasion revealed that the abscess had not recurred.

Limited susceptibility data are available. Strains of A meyeri are usually susceptible to penicillin, chloramphenicol, erythromycin and tetracycline (1). Since so few susceptibility tests have been reported, it may be advisable to determine susceptibilities on individual strains isolated from patients with severe infections. The optimal duration of antibiotic therapy for actinomycotic endocarditis has not yet been determined. In the eight previously described cases, antibiotics were administered from between four weeks and 10 months (9). One patient who received four weeks of intravenous penicillin relapsed three weeks after treatment was stopped. In this case, six weeks of penicillin was administered. In this case, a shorter course (six weeks) of penicillin was administered because cultures taken at surgery were negative and because the involved valve had been replaced.

In our patient, diagnosis was delayed because of a lack of

\section{REFERENCES}

1. Cato EP, Moore WEC, Nygaard G, Holdeman LV. Actinomyces meyeri sp. nov., specific epithet rev. Int J System Bacteriol 1984;34:487-9.

2. Miyamoto MI, Fang FC. Pyogenic liver abscess involving actinomyces: case report and review. Clin Infect Dis 1993; 16:303-9.

3. Allen JN. Actinomyces meyeri breast abscess. Am J Med 1987;83:186-7.

4. Pordy RC. Lumpy jaw due to Actinomyces meyeri: report of the first case and review of the literature. Mt Sinai J Med 1988;55:190-3

5. Rose HD, Varkey B, Kutty CPK. Thoracic actinomycosis due to Actinomyces meyeri. Am Rev Respir Dis 1982;125:251-4. signs and symptoms of infection and because the blood culture isolate was initially considered a likely contaminant. This is not surprising since the vast majority of nonspore-forming Gram-positives from blood cultures represent contaminants. Even when the second blood culture became positive, it was first reported as a 'diphtheroid' and was only identified as A meyeri when it became known that a similar isolate had been recovered three weeks before and that the patient likely had endocarditis.

\section{CONCLUSIONS}

We report the first case of bacterial endocarditis attributable to A meyeri in a man with severe destructive rheumatoid arthritis. Although the underlying rheumatoid arthritis and anti-inflammatory therapy may have led to modest impairment of host defence mechanisms, it is not possible to attribute significance based on a single case. Previously reported cases of Actinomyces species endocarditis have not been associated with significant immune compromise. The infection occurred without an apparent source and required aortic valve replacement. The endocarditis initially went unrecognized because of the lack of symptoms and signs of infection and because the organism was initially considered a contaminant. The patient was cured with a six-week course of high dose penicillin.

6. Pang DK, Abdalla M. Osteomyelitis of the foot due to Actinomyces meyeri. Foot Ankle 1987;8:169-71.

7. Kuijper EJ, Wiggerts HO, Jonker GJ, Schaal KP, DeGans J. Disseminated actinomycosis due to Actinomyces meyeri and Actinobacillus actinomycetemcomitans. Scand J Infect Dis 1992;24:667-72.

8. Marty HU, Wust J. Disseminated actinomycosis caused by Actinomyces meyeri. Infection 1989;17:154-5.

9. Lam S, Samraj J, Hilton E. Primary actinomycotic endocarditis: case report and review. Clin Infect Dis 1993;16:481-5.

10. Brander MA, Jousimics-Somer HR. Evaluation of the RapID ANAII and API ZYM systems for identification of Actinomyces species from clinical specimens. J Clin Microbiol 1992;30:3112-6. 


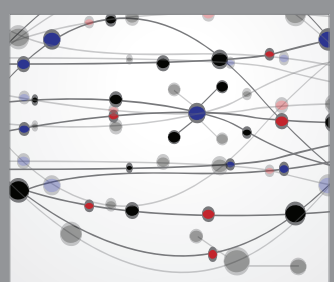

The Scientific World Journal
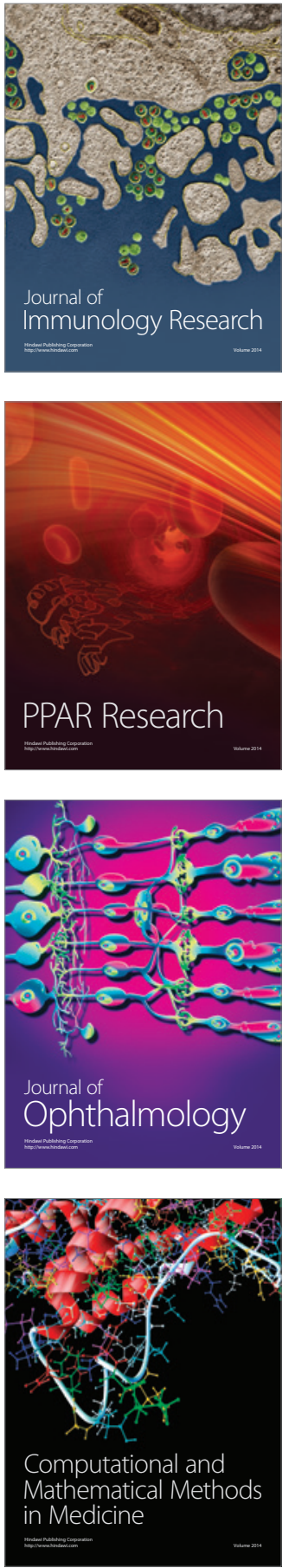

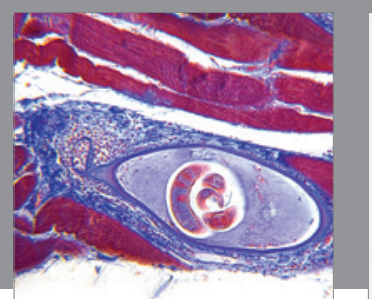

Gastroenterology Research and Practice

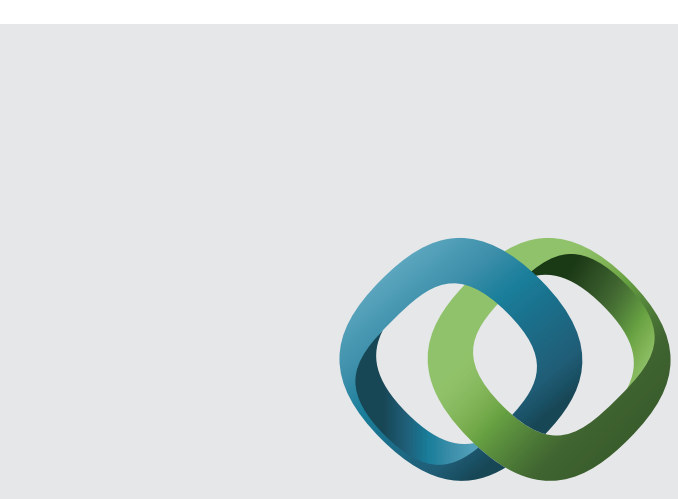

\section{Hindawi}

Submit your manuscripts at

http://www.hindawi.com
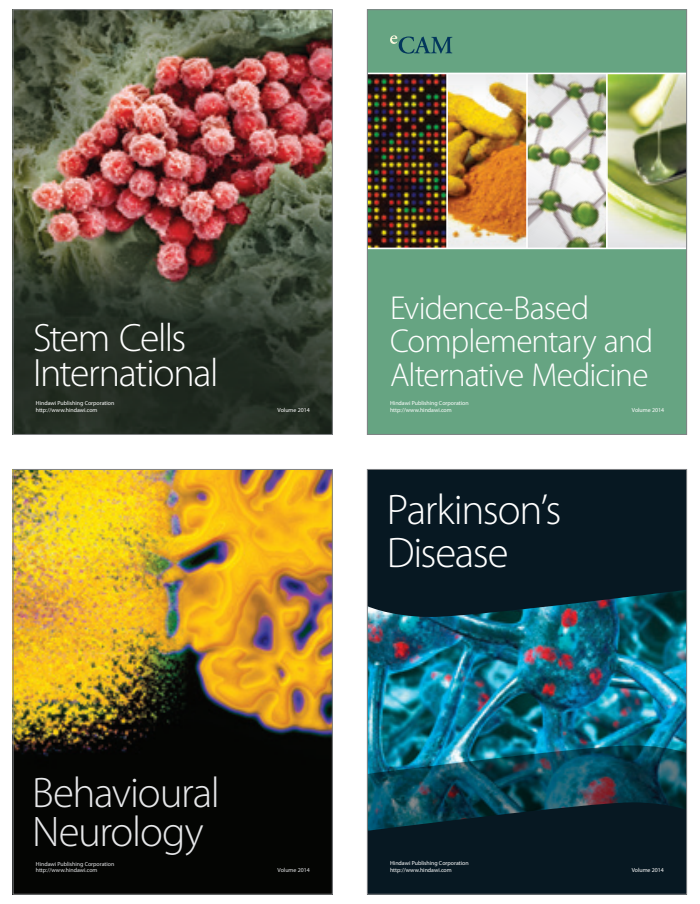
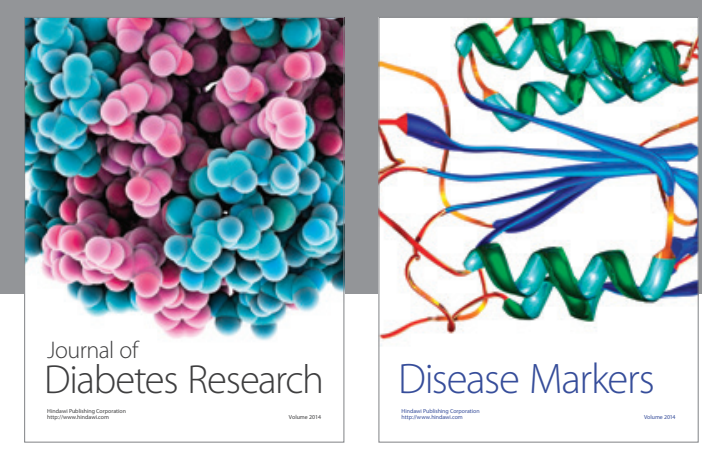

Disease Markers
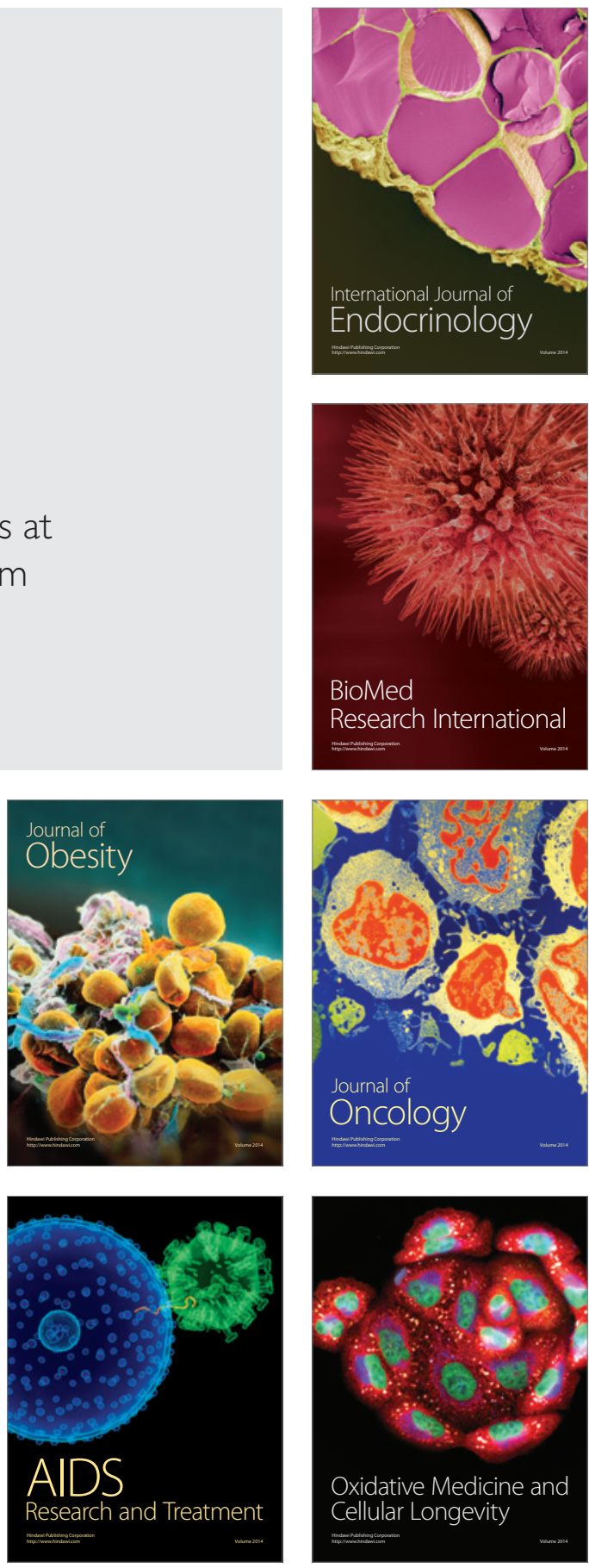